\title{
Effect of microencapsulated granulas contained in the natural extracts on
}

\section{postsurgical wound healing}

Tomislav Katanec ${ }^{1}$, Martina Majstorović ${ }^{2}$, Davor Katanec ${ }^{3}$, Ivona Bago ${ }^{4}$, Luka Marković1 ${ }^{1}$, and Dragana Gabrić ${ }^{3}$

1. University Dental Clinic, University Hospital Center, Zagreb, Croatia

2. Department of Paediatric and Preventive Dentistry, School of Dental Medicine, University of Zagreb,

University Hospital Center, Zagreb, Croatia

3. Department of Oral Surgery, School of Dental Medicine, University of Zagreb, University Hospital Center, Zagreb, Croatia

4. Department of Endodontics and Restorative Dentistry, School of Dental Medicine, University of Zagreb, Zagreb, Croatia

\section{RESEARCH}

Please cite this paper as: Please cite this paper as: Katanec T, Majstorović M, Katanec D, Bago I, Marković L, Gabrić D. Effect of microencapsulated granulas contained in natural extracts on postsurgical wound healing. AMJ 2020;13(4):106-113.

https://doi.org/10.35841/1836-1935.13.4.106-113

\section{Corresponding Author:}

Associate Professor Dragana Gabrić, DDM, PhD

Department of Oral Surgery, School of Dental Medicine, University of Zagreb, University Hospital Center, Gundulićeva 5, HR-10000 Zagreb, Croatia

Phone: +38514802138

Fax: +38514802159

Email: dgabric@sfzg.hr

\section{ABSTRACT}

\section{Background}

The innovative complex technology of encapsulation of the natural extracts allows the products to be more efficient in surgical wound healing due to penetration of the microcapsules in the soft tissues.

\section{Aims}

The aim of the randomized controlled trial was to evaluate the effectiveness of microencapsulated natural extracts contained in the gel on wound healing process after oral surgical procedures.

\section{Methods}

The study included 95 patients with indications for endodontic surgery: third molar surgical extraction or dental implants placement. The patients were randomly divided in two groups based on the postsurgical protocol on treating the wound after surgery: A/: Subgroup 1: GinGinat group used a gel composed of different natural products (GinGinat gel, LoB Foundation, Paris, France) for treating the surgical area; B/ Subgroup 2: Standard protocol used saline solution for treating the wound after surgery. At the seven day follow upallpatients were asked to rate their experience and satisfaction on the recovery process after surgery based on a questionnaire. They were observed and evaluated for satisfaction with the recovery process based on using Likerttype scale.

\section{Results}

The results showed a statistically significant difference in the postoperative recovery period between the GinGinat and standard group $(p<0.001)$ based on a therapist's evaluation. The GinGinat group was rated with the higher clinical score compared to the standard group $(p<0.001)$. There was a statistically significant difference in the recovery postoperative period between the GinGinat and standard group as rated based on the results of a patient's questionnaire $(p<0.001)$.

\section{Conclusion}

The results showed clinical improvement and better postsurgical healing of the wounds as well as the stronger analgesic effect after the application of microencapsulated granulas which are contained in the natural extracts as opposed to the standard postsurgical protocol. 


\section{Key Words}

Wound healing, microencapsulation, essential oil, plant extracts, oral surgery

\section{What this study adds:}

\section{What is known about this subject?}

A new product proved efficient in inducing better wound healing in the recovery process following surgical intervention, such as third molar removal, apicoectomy, and dental implant placement.

\section{What new information is offered in this study?}

Dental plaque reduction, analgesic effect and better wound healing was induced by Ginginat gel and it can be attributed to its microcapsulated natural ingredients.

3. What are the implications for research, policy, or practice?

Natural extracts can be considered as an efficient approach in the postsurgical oral hygiene protocol instead of the standard saline solution rinse.

\section{Background}

Bacterial flora, which constitutes dental plaque represents the primary and most responsible factor in aetiology of periodontal diseases and oral inflammations. The bacteria which form biofilm can become aggressive and provoke tissue destruction, either directly through enzymatic reactions and bacterial toxins, or indirectly inducing inflammatory reaction of the host tissues. Consequently, the tissue response ultimately determines a higher or lower degree of bacterial aggression. ${ }^{1,2}$ Some strains of bacteria, such as Porphyromonas gingivalis and Treponema denticola, can be particularly harmful to the gingiva due to infection which results from organization and maturation of bacterial biofilm that adheres to tissue. ${ }^{3-5}$ It has been proved that periodontal diseases are of inflammatory origin and as such involve local pathologic reactions of the affected tissue. In such cases, anti-inflammatory agents and antibacterials are commonly used in treating acute inflammation. A therapeutic approach in eliminating potentially aggressive bacterial flora is either mechanical (brushing, detartrating, scaling), or chemical, based on using adjuvants like chlorhexidine, triclosan, cetylpypiridinium chloride, orgels, mouthwashes, etc. They are efficient, however, rather aggressive due to low-specific strategy, which results in significantly damaging most bacterial species which further results in an imbalance and disequilibrium of the oral ecosystems a whole. It further can deteriorate due to the consequences, which result from the limited time available in planning therapy as well as disability to treat the tissue ground. At the same time, this approach is rather aggressive as it destabilizes the bacterial equilibrium in the mouth. It has been proved that mouthwashes conventionally represent access to only temporary antisepsis by allowing the removal of damaged tissue wounds, but on the other hand are chemically non-selective in eliminating bacterial flora. $^{6-8}$

In order to treat the tissue ground and to re-equilibrate the oral environment and relieve from pathologically related consequences, different natural extracts are available. Some of the natural extracts that can be used in the oral cavity are: avocado oil (effect on the modulation of the inflammation and healing process stimulation), Manuka oil (strong antiseptic effect), Propolis (antiseptic and antiinflammatory effect), and grapefruit seed extracts (antioxidant and antimicrobal effect). The innovative complex technology of encapsulation of the natural extracts allows the products to be more efficient and release active substances during six to eight hours, due to penetration of the microcapsules in the soft tissues. The GinGinat gel (GingiNat, LoB Foundation, Paris, France) is a new concept of microencapsulated granulas contained in the natural extracts (propolis, grapefruit seed extract, coenzym Q10, Manuka oil, paracress, avocado oil, chitosan, aloe vera, rosemary leaf extract, calcium and zinc minerals). According to the manufacturer, it has antiseptic effect on the periodontal pathogens, buffer effect in $\mathrm{pH}$ regulation, antioxidant effect in reducing oxidative stress associated with bacterial aggression, immunoregulatory effect limiting tissue damage induced by chronic inflammation, and analgesic effect. It promotes healing as well. ${ }^{9,10}$

The aim of this clinical study was to evaluate the effectiveness of the microencapsulated natural extracts on wound healing process after different oral surgical procedures.

\section{Patients and Methods}

The randomized controlled trial was performed at the Department of Oral Surgery, School of Dental Medicine, University of Zagreb and University Hospital Centre Zagreb in the period of December 2015 and October 2016. This clinical study followed the Helsinki Declaration on medical protocol and ethics and was approved by the regional Ethical Review Board. All participants signed informed consent agreements prior to commencing the study.

\section{Sample frame}

The study sample included 95 participants ( 40 males and 55 
females) who were aged between 25 and 50 years and were scheduled for oral surgical procedures. The inclusion criteria were: endodontic surgery, surgical third molar removal and dental implants placement. The exclusion criteria were: juvenile population, acute inflammation and intake of analgesics, antimicrobial therapy and/or anticoagulant medications taken one month prior to the procedure. A total of 120 surgical treatments were performed: 1 ) The first group comprised of 50 patients who underwent endodontic surgery (each patient underwent one apical root resection treatment); 2) The second group comprised of 25 patients who underwent bilateral surgical removal of the third lower molars (in each patient lower third molars were extracted bilaterally, which in total comprised 50 extractions), and 3) The third group comprised of 20 patients who underwent the surgical procedure for dental implant placement (NobelReplaceTM, Nobel Biocare, Sweden) (in each patient minimally two implants were loaded bilaterally in the six month time interval). In the third group, lateral approach of sinus floor elevation procedure combined with immediate implant placement was performed.

According to the postsurgical protocol used in order to promote healing and reducing the symptoms of pain and inflammation after surgery, each group was further divided in two subgroups: 1) The first subgroup (GinGinat group) used a gel composed of different natural products (GinGinat gel, LoB Foundation, Paris, France) for treating the surgical area; 2) The second subgroup used a traditional method of rinsing with saline solution for treating the surgical area. Patients from the endodontic surgery groups were divided into following subgroups 25 patients tested group (GinGinat) and 25 patients control group (saline); patients from the third molar removal group right side of the jaw tested group (GinGinat) and left side of the jaw control group (saline); patients from the implant placement group 10 patients tested group (GinGinat) and 10 patients control group (saline).

The patients were randomly selected for each group by choosing a closed envelope, which specified the group they were assigned to. Oral surgeon, who performed surgery, did not know to which group the patients were assigned to. Another oral surgeon maintained records about the patients.

All surgical procedures were performed by one experienced oral surgeon. The surgical procedures were performed by using local anaesthesia (Ubistesin 2 per cent, 3M ESPE, Seefeld, Germany), up to $4 \mathrm{ml}$, depending on the surgical indication. In performing surgery, wounds were stitched by using 5/0 thick and $75 \mathrm{~cm}$ long sterile, non-resorbable, silky braided and coated thread (Silkam, Aesculap, USA). The round cross section needle was used.

All patients followed the same postoperative oral hygiene protocol which is a standard protocol used at the Department of Oral Surgery. The patients from the GinGinat group (Subgroup 1) were given detailed instructions on how to use GinGinat gel: each patient was instructed to apply a thin layer of the gel on the surgical area three times per day, in the morning, afternoon and evening, in a period of seven days. In subgroup 2, the surgical area was rinsed with $6 \mathrm{ml}$ saline solution (for three minutes per session) by using the same daily routine in the period of seven days.

By completing the postoperative oral hygiene protocol, patients were asked to rate their experience and satisfaction and give their opinion on the recovery process based on the questionnaire. At the follow-up visits, all patients were seen by the same oral surgeon who rated their satisfaction by using Likert-type scale. At the same day, stitches were removed by the same therapist and aproximal plaque index (API) for each patient in the tested and control group were measured. Plaque finding at the surgical site was indicated as positive and plaque deficiency as negative finding. Aproximal laque index for the endodontic surgery group was measured on adjacent teeth located to the left and right of the postsurgical area; for the third molar removal group was measured on the mesial adjacent tooth; for the dental implants group on the mesial adjacent tooth.

\section{Statistical analysis}

Statistical analysis was conducted by using SPSS for Windows Release 7.5.1 (1996). Normality of the distribution was tested by using Kolmogorov-Smirnov test and $\chi 2$ test and Pearson's correlation were used for further analysis. $\mathrm{P}$ values lower than 0.05 were considered significant.

\section{Results}

Unintended effects in the recovery period were not recorded. There were no losses and exclusions in the study. The results showed a statistically significant difference in the postoperative recovery period between the GinGinat and standard groups $(p<0.001)$.

The results of the Likert scale showed higher clinical scores for the Ginginat group compared to the patients who used the standard postoperative protocol (Table 1). The Fischer's exact test showed a statistically significant difference $(p<0.001)$ between the GinGinat group vs. standard group: of the total number of patients from the GinGinat group, 
100 per cent of them would recommend using the gel in other surgical procedures.

Table 2 represents a statistically significant difference in the scores between the GinGinat and standard groups, as rated by patients. According to the results based on Likert scale, the GinGinat patients scored higher than controls for all tested parameters $(p<0.001)$. The Fischer's Exact test showed a statistically significant difference between the patients who used the gel and felt the effect for 2-3 hours postoperatively as opposed to the patients who used the standard protocol and in whom the effect lasted for only 12 hours $(p<0.001)$. Table 3 shows the results based on the patients' evaluation of postsurgical recovery process and as such presents a significant difference between the GinGinat and standard groups $(p<0.001)$. A total of 100 per cent patients from the GinGinat group would be willing to continue using the gel, as opposed to 56.7 per cent of the patients from the group which used the traditional method, who would not be willing to continue using the same method again $(p<0.001)$.]

\section{Discussion}

Due to its properties, the microencapsulated granulas contained in the natural extracts could modulate the inflammatory reactions and have potential analgesic as well as a strong antiseptic treatment effect, thus protecting the wounds and enhancing soft tissue healing. ${ }^{9,10}$ So far this combination of natural ingredients contained in either gel or mouthwash, have showed some efficiency in treating oral lesions, such as lichen and various forms of ulcers in medically compromised patients. However, data is still lacking, particularly on the potential effect on wound healing after surgery. This study aimed specifically at evaluating the effect of the gel after oral surgical procedures, which included extractions, implant placement and endodontic surgery.

The overall results of the study showed a significant improvement in regards to wound healing, inflammatory reactions and pain control in the patients who were treated with the gel in comparison with the patients who used the traditional method in the postsurgical treatment. No difference with respect to the type of surgical procedure was observed within the group of the patients who used the gel. The clinical symptoms in the postsurgical recovery period equally improved in the patients who were treated for extractions, implant surgery and apicoectomy.

In general, many natural extracts have been used in order to treat oral pathologies or at least to relieve and/or reduce cause-related pathological consequences. Except for antibacterial effects, the real clinical effect of these natural extracts in the available mouthwashes have still been debated. ${ }^{9,10}$ These products are intended to treat tissue by enhancing re-equilibrium of oral bacterial flora environment. ${ }^{9}$ Although these products have proved efficient, they seem to be aggressive and low specific as they may damage most of the oral pathogens. It consequently leads to disequilibrium and conversely tend to deteriorate the clinical symptoms. ${ }^{10,11}$ For this particular reason, they are recommended for temporary usage, which certainly represents a significant drawback. ${ }^{12}$

According to the results obtained in this study, the gel offers an improvement in treating such cases as the overall objective of its concept seem to represent a global approach in treating oral tissue ground due to possible disintegration of dental plaque and improvement of the host tissue response. In order to offer a sustained and indepth effect in the gingival and mucous tissues, the natural extracts and minerals in the gel were combined in the form of microcapsules, which penetrate within the tissues and facilitate prolonged and deferred tissue reactions. In general, microincapsulation provides excellent cutaneous and mucosal adhesion, stabilization of encapsulated preparation and extension of the half-life of the preparation in situ. It also gives a possibility of mixing various ingredients without denaturation as well as their immediate release on the application site. ${ }^{9}$ This tells for a prolonged and targeted performance of the gel, which in this study proved to be effective in the GinGinat group of patients.

The prolonged effect of pain control, lack of burning sensation and the overall better sensation in the mouth, which was present in the GinGinat group of the patients can be attributed to a slow release of its active principles, which is approximated to 6-8 hours The expected clinical outcomes in the postsurgical recovery period in the GinGinat group were related to its antiseptic, immunoregulatory, analgesic, healing and antioxidant effects and can be attributed to the natural ingredients which are integrated in the microcapsules. Manuka and avocado oil, paracress, and chitosan proved a strong antibacterial effect, which in the GinGinat group contributed to a decrease in the key oral pathogens, and was responsible for maintaining the equilibrium of the buffer capacity in the mouth. ${ }^{13-15}$ In the postsurgical recovery period, it particularly affected the sites around wounds, which in the GinGinat group enhanced better healing. Along with that, reduction of dental plaque was observed as well. Furthermore, aloe vera and paracress 
have proved as anti-inflammatory agents, which consequently explained a significant reduction in redness and clinical signs of inflammation in the GinGinat group. ${ }^{16,17}$ Rosemary leaf extract proved a strong analgesic effect, which together with paracress and its numbing effect, yielded a stronger pain relief in the GinGinat group as well. ${ }^{18}$ A significant difference in the GinGinat group, as opposed to the standard group which used the traditional method, was observed due to its long lasting effect, which in 66.7 per cent of the patients was 2-3 hours and in 21.7 per cent of them even more than 3 hours. On the contrary, this analgesic effect was less than an hour in patient who used the traditional method. It lasted minimally in the traditional group, which was 1-2 hours in 50 per cent of the patients. More than satisfying clinical results due to the impact of this new concept could be related to a strong atiseptic and antiinflammatory effects of propolis and grapefruit seeds, but also to other enzymes and minerals which are contained in the gel, as they represent significant buffer, antioxidant and antibiotic agents. ${ }^{19-21}$

\section{Conclusion}

The results of the present study showed a significant clinical improvement with respect to better postsurgical healing of the wounds and stronger analgesic effect when using the microencapsulated granulas contained in the natural extracts, as compared to the standard protocol used traditionally in the postoperative healing process.

\section{References}

1. Al Jehani YA. Risk factors of periodontal disease: review of the literature. Int J Dent. 2014;2014:182513.

2. Pussinen PJ, Paju S, Mäntylä P, et al. Serum microbialand host-derived markers of periodontal diseases: a review. Curr Med Chem. 2007;14(22):2402-12.

3. Ammann TW, Bostanci N, Belibasakis GN, et al. Validation of a quantitative real-time PCR assay and comparison with fluorescence microscopy and selective agar plate counting for species-specific quantification of an in vitro subgingival biofilm model. J Periodontal Res. 2013;48(4):517-26.

4. Meuric V, Martin B, Guyodo H, et al. Treponema denticola improves adhesive capacities of Porphyromonas gingivalis. Mol Oral Microbiol. 2013;28(1):40-53.

5. Booth V, Lehner $T$. Characterization of the Porphyromonas gingivalis antigen recognized by a monoclonal antibody which prevents colonization by the organism. J Periodontal Res. 1997;32(1 Pt 1):54-60.

6. Rode S de M, Gimenez X, Montoya VC, et al. Daily biofilm control and oral health: consensus on the epidemiological challenge--Latin American Advisory Panel. Braz Oral Res. 2012;26 Suppl 1:133-43.

7. Theilade $E$. The non-specific theory in microbial etiology of inflammatory periodontal diseases. J Clin Periodontol. 1986;13(10):905-11.

8. Loesche WJ. Clinical and microbiological aspects of chemotherapeutic agents used according to the specific plaque hypothesis. J Dent Res. 1979;58(12):2404-12.

9. Mouhyi J, Dei C-Orso M, Hippolyte MP, et al. Mouthwash solutions containing microencapsulated natural extracts: In vitro evaluation of antioxidant properties (dental plaque and gingivitis). Rev Stomatol Chir Maxillofac. 2010;111(3):144-7.

10. Jones CG. Chlorhexidine: is it still the gold standard? Periodontol 2000. 1997;15:55-62.

11. Stoeken JE, Paraskevas S, Van der Weijden GA. The long-term effect of a mouthrinse containing essential oils on dental plaque and gingivitis: a systematic review. J Periodontol. 2007;78(7):1218-28.

12. Charles $\mathrm{CH}$, Mostler KM, Bartels LL, et al. Comparative antiplaque and antigingivitis effectiveness of a chlorhexidine and an essential oil mouthrinse: 6-month clinical trial. J Clin Periodontol. 2004;31(10):878-84.

13. Nayak BS, Raju SS, Chalapathi Rao AV. Wound healing activity of Persea americana (avocado) fruit: a preclinical study on rats. J Wound Care. 2008;17(3):123-6.

14. Takarada K, Kimizuka R, Takahashi N, et al. A comparison of the antibacterial efficacies of essential oils against oral pathogens. Oral Microbiol Immunol. 2004;19(1):61-4.

15. English HK, Pack AR, Molan PC. The effects of manuka honey on plaque and gingivitis: a pilot study. J Int Acad Periodontol. 2004;6(2):63-7.

16. Maenthaisong R, Chaiyakunapruk N, Niruntraporn S, et al. The efficacy of aloe vera used for burn wound healing: a systematic review. Burns. 2007;33(6):713-8.

17. Wu LC, Fan NC, Lin MH, et al. Anti-inflammatory effect of spilanthol from Spilanthes acmella on murine macrophage by down-regulating LPS-induced inflammatory mediators. J Agric Food Chem. 2008;56(7):2341-9.

18. Takaki I, Bersani-Amado LE, Vendruscolo A, et al. Antiinflammatory and antinociceptive effects of Rosmarinus officinalis L. essential oil in experimental animal models. J Med Food. 2008;11(4) 741-6.

19. Barroso PR, Lopes-Rocha R, Pereira EM, et al. Effect of propolis on mast cells in wound healing. Inflammopharmacology. 2012;20(5):289-94.

20. Al-Shaher A, Wallace J, Agarwal S, et al. Effect of propolis on human fibroblasts from the pulp and 
periodontal ligament. J Endod. 2004;30(5):359-61.

21. Dall'Asta $M$, Derlindati $E$, Curella $V$, et al. Effects of naringenin and its phase II metabolites on in vitro human macrophage gene expression. Int J Food Sci Nutr. 2013;64(7):843-9.

\section{PEER REVIEW}

Not commissioned. Externally peer reviewed.

\section{CONFLICTS OF INTEREST}

The authors declare that they have no competing interests.

\section{FUNDING}

None

\section{ETHICS COMMITTEE APPROVAL}

Ethical Committee, School of Dental Medicine, University of Zagreb, No 0016/15 
Table 1: Clinical evaluation of postsurgical treatment (oral surgeon)

\begin{tabular}{|c|c|c|c|c|c|c|c|}
\hline Question & & & $\begin{array}{l}\text { Very } \\
\text { bad }\end{array}$ & Bad & Modate & Good & $\begin{array}{l}\text { Very } \\
\text { good }\end{array}$ \\
\hline \multirow[t]{4}{*}{ Patients satisfaction } & \multirow[t]{2}{*}{ Gel } & $\mathrm{n}$ & & & & 9 & 51 \\
\hline & & $\%$ & & & & $15.0 \%$ & $85.0 \%$ \\
\hline & \multirow[t]{2}{*}{ Saline solution } & $\mathrm{n}$ & 4 & 24 & 32 & & \\
\hline & & $\%$ & $6.7 \%$ & $40.0 \%$ & $53.3 \%$ & & \\
\hline \multirow[t]{4}{*}{ Soft tissue healing } & \multirow[t]{2}{*}{ Gel } & $\mathrm{n}$ & & & & 6 & 54 \\
\hline & & $\%$ & & & & $10.0 \%$ & $90.0 \%$ \\
\hline & \multirow[t]{2}{*}{ Saline solution } & $\mathrm{n}$ & 7 & 24 & 28 & 1 & \\
\hline & & $\%$ & $11.7 \%$ & $40.0 \%$ & $46.7 \%$ & $1.7 \%$ & \\
\hline \multirow[t]{4}{*}{ Reduction of dental plaque } & \multirow[t]{2}{*}{ Gel } & $\mathrm{n}$ & & & 6 & 28 & 26 \\
\hline & & $\%$ & & & $10.00 \%$ & $46.70 \%$ & $43.30 \%$ \\
\hline & \multirow[t]{2}{*}{ Saline solution } & $\mathrm{n}$ & 10 & 23 & 26 & 1 & \\
\hline & & $\%$ & $16.7 \%$ & $38.3 \%$ & $43.3 \%$ & $1.7 \%$ & \\
\hline \multirow{4}{*}{$\begin{array}{l}\text { Control of pain and } \\
\text { inflammation }\end{array}$} & \multirow[t]{2}{*}{ Gel } & $\mathrm{n}$ & & & 1 & 15 & 44 \\
\hline & & $\%$ & & & $1.7 \%$ & $25.0 \%$ & $73.3 \%$ \\
\hline & \multirow[t]{2}{*}{ Saline solution } & $\mathrm{n}$ & 1 & 24 & 35 & & \\
\hline & & $\%$ & $1.7 \%$ & $40.0 \%$ & $58.3 \%$ & & \\
\hline \multirow[t]{4}{*}{ Postoperative recovery } & \multirow[t]{2}{*}{ Gel } & $\mathrm{n}$ & & & & & 60 \\
\hline & & $\%$ & & & & & $100.0 \%$ \\
\hline & \multirow[t]{2}{*}{ Saline solution } & $n$ & 5 & 26 & 29 & & \\
\hline & & $\%$ & $8.3 \%$ & $43.3 \%$ & $48.3 \%$ & & \\
\hline
\end{tabular}

Table 2: Clinical evaluation of postsurgical treatment (observed by patient)

\begin{tabular}{|c|c|c|c|c|c|c|c|}
\hline Question & Gel & & Very bad & Bad & Moderate & Good & $\begin{array}{l}\text { Very } \\
\text { good }\end{array}$ \\
\hline \multirow{4}{*}{$\begin{array}{l}\text { Sensation in the mouth } \\
\text { during and after usage } \\
\text { of GinGinat (no burning } \\
\text { sensation) }\end{array}$} & \multirow{2}{*}{ Gel } & $\mathrm{n}$ & & & 1 & 23 & 36 \\
\hline & & $\%$ & & & $1.70 \%$ & $38.30 \%$ & $60.00 \%$ \\
\hline & \multirow{2}{*}{$\begin{array}{l}\text { Saline } \\
\text { solution }\end{array}$} & $\mathrm{n}$ & 3 & 27 & 27 & 3 & \\
\hline & & $\%$ & $5.00 \%$ & $45.00 \%$ & $45.00 \%$ & $5.00 \%$ & \\
\hline \multirow{4}{*}{ Long lasting fresh breath } & \multirow{2}{*}{ Gel } & $\mathrm{n}$ & & & 9 & 31 & 20 \\
\hline & & $\%$ & & & $15.00 \%$ & $51.70 \%$ & $33.30 \%$ \\
\hline & \multirow{2}{*}{$\begin{array}{l}\text { Saline } \\
\text { solution }\end{array}$} & $\mathrm{n}$ & 5 & 30 & 21 & 4 & \\
\hline & & $\%$ & $8.30 \%$ & $50.00 \%$ & $35.00 \%$ & $6.70 \%$ & \\
\hline \multirow{4}{*}{$\begin{array}{l}\text { Reduction of dental } \\
\text { plaque }\end{array}$} & \multirow{2}{*}{ Gel } & $n$ & & & 9 & 25 & 26 \\
\hline & & $\%$ & & & $15.00 \%$ & $41.70 \%$ & $43.30 \%$ \\
\hline & \multirow{2}{*}{$\begin{array}{l}\text { Saline } \\
\text { solution }\end{array}$} & $n$ & 4 & 31 & 21 & 4 & \\
\hline & & $\%$ & $6.70 \%$ & $51.70 \%$ & $35.00 \%$ & $6.70 \%$ & \\
\hline \multirow{4}{*}{$\begin{array}{l}\text { Reduction of bleeding } \\
\text { and inflammation } \\
\text { (redness) }\end{array}$} & \multirow{2}{*}{ Gel } & $\mathrm{n}$ & & & 4 & 24 & 32 \\
\hline & & $\%$ & & & $6.70 \%$ & $40.00 \%$ & $53.30 \%$ \\
\hline & \multirow{2}{*}{$\begin{array}{l}\text { Saline } \\
\text { solution }\end{array}$} & $n$ & 1 & 14 & 35 & 10 & \\
\hline & & $\%$ & $1.70 \%$ & $23.30 \%$ & $58.30 \%$ & $16.70 \%$ & \\
\hline \multirow{3}{*}{$\begin{array}{l}\text { Relieve of pain or } \\
\text { unpleasant feeling } \\
\text { around the wound }\end{array}$} & \multirow{2}{*}{ Gel } & $n$ & & & 1 & 14 & 45 \\
\hline & & $\%$ & & & $1.70 \%$ & $23.30 \%$ & $75.00 \%$ \\
\hline & Saline & $\mathrm{n}$ & 2 & 15 & 34 & 9 & \\
\hline
\end{tabular}




\begin{tabular}{|l|c|c|c|c|c|c|c|} 
& solution & $\%$ & $3.30 \%$ & $25.00 \%$ & $56.70 \%$ & $15.00 \%$ & \\
\hline \multirow{3}{*}{$\begin{array}{l}\text { Healing of aphtae and } \\
\text { wounds associated with } \\
\text { surgery }\end{array}$} & Gel & $\mathrm{n}$ & & & 1 & 12 & 47 \\
\cline { 2 - 9 } & $\%$ & $\%$ & & & $1.70 \%$ & $20.00 \%$ & $78.30 \%$ \\
\cline { 2 - 9 } & $\begin{array}{c}\text { Without } \\
\text { Saline } \\
\text { solution }\end{array}$ & $\mathrm{n}$ & 3 & 18 & 34 & 5 & \\
\cline { 3 - 9 } & & $\%$ & $5.00 \%$ & $30.00 \%$ & $56.70 \%$ & $8.30 \%$ & \\
\hline
\end{tabular}

Table 3: The results of $\chi^{2}$ test based on patient evaluation of postsurgical recovery

\begin{tabular}{|c|c|c|c|c|}
\hline Question & GinGinat & & No & Yes \\
\hline \multirow{4}{*}{$\begin{array}{l}\text { Have you noticed any sign of } \\
\text { intolerance / adverse side effects? }\end{array}$} & \multirow[t]{2}{*}{ Gel } & $\mathrm{n}$ & 60 & \\
\hline & & $\%$ & 100.0 & \\
\hline & \multirow[t]{2}{*}{ Saline solution } & $\mathrm{n}$ & 60 & \\
\hline & & $\%$ & $100.0 \%$ & \\
\hline \multirow{4}{*}{$\begin{array}{l}\text { Are you willing to continue using the } \\
\text { method? }\end{array}$} & \multirow[t]{2}{*}{ Gel } & $\mathrm{n}$ & & 60 \\
\hline & & $\%$ & & $100.0 \%$ \\
\hline & \multirow[t]{2}{*}{ Saline solution } & $\mathrm{n}$ & 34 & 26 \\
\hline & & $\%$ & $56.7 \%$ & $43.3 \%$ \\
\hline \multirow{4}{*}{$\begin{array}{l}\text { After this experience are you willing } \\
\text { to buy GinGinat (regardless of price)? }\end{array}$} & \multirow[t]{2}{*}{ Gel } & $\mathrm{n}$ & & 60 \\
\hline & & $\%$ & & $100.0 \%$ \\
\hline & \multirow[t]{2}{*}{ Saline solution } & $\mathrm{n}$ & 44 & 16 \\
\hline & & $\%$ & $73.3 \%$ & $26.7 \%$ \\
\hline
\end{tabular}

